\title{
Differences in Patterns of Participation Between Youths With Cerebral Palsy and Typically Developing Peers
}

\author{
Batya Engel-Yeger, Tal Jarus, Dana Anaby, and Mary Law
}

\author{
KEY WORDS \\ - cerebral palsy \\ - leisure activities \\ - peer group \\ - self-assessment (psychology) \\ - sex factors
}

OBJECTIVE. This study investigated the effects of cerebral palsy (CP) and gender on youth participation in activities outside of formal school.

METHOD. Twenty-two participants with CP and 30 typically developing peers, ages 12-16 years, completed the Children's Assessment of Participation and Enjoyment (CAPE; King et al., 2004).

RESULTS. Typically developing youths engaged in a broader range of activities and did so more frequently than did youths with CP. Similar levels of enjoyment in activity were found in both groups. In some scales of the CAPE, youths with CP participated in proportionally more activities alone and at home. Gender differences and Group $\times$ Gender interaction were found in some scales with respect to participation in and enjoyment of activities.

CONCLUSIONS. Physical limitations associated with CP may affect the frequency of a child's participation in activity outside of school. However, youths with CP may express levels of enjoyment similar to those of typically developing peers while participating in activity.

Engel-Yeger, B., Jarus, T., Anaby, D., \& Law, M. (2009). Differences in patterns of participation between youths with cerebral palsy and typically developing peers. American Journal of Occupational Therapy, 63, 96-104.

$T^{\text {he }}$ he World Health Organization (WHO) defines participation as the nature and extent of a person's involvement in life situations and categorizes participation in terms of personal maintenance; mobility; information exchange; social relationships; home life; education; work and employment; economic life; and community, social, and civic life (WHO, 2001). Participation leads to life satisfaction as well as a sense of competence and is essential for psychological and emotional well-being and skill development. Complicated physical disabilities and the social and emotional difficulties that accompany them, as well as a child's ongoing treatment, may affect several aspects of well-being and reduce his or her participation in activity (King et al., 2006).

Cerebral palsy (CP) is one of the most common severe physical disabilities that affects children. In the United States, CP affects approximately $0.2 \%$ of neonatal survivors (Moe \& Seay, 1993). Children who have CP have had demonstrable increases in their life expectancy over the course of the past 20 years. For example, according to Strauss, Shavelle, Reynolds, Rosenbloom, and Day (2007), an appreciable improvement over time was found in children with severe disabilities and in adults who required gastrostomy feeding. In these groups, mortality rates fell by $3.4 \%$ per year. Children with CP often require life-long intervention that may involve drug therapy, surgery, and treatment by various health professionals such as occupational, physical, and speech therapists.

Stevenson, Pharoah, and Stevenson (1997) found that young adults with CP were less socially active, participated in fewer leisure activities, and were more socially isolated than typically developing peers. Margalit (1981) studied leisure activities of 
51 children with CP in comparison to children with no disability and found that the activities of children with CP were mostly at home and depended on adults (parents and teachers). Their activities were limited, were suitable for younger children, and encouraged a passive lifestyle. Researchers also have reported that children with physical disabilities tend to engage in less varied leisure activities than children without disabilities and that their participation is characterized by a greater frequency of quiet recreation activities and fewer social activities, especially social activities of a spontaneous nature (Brown \& Gordon, 1987; King et al., 2006; Law et al., 2006; Margalit, 1981; Meijer, Sinnema, Bijstra, Mellenbergh, \& Wolters, 2000).

The literature indicates that environmental factors (e.g., the physical accessibility of buildings and attitudes of community members), familial factors (e.g., supportive modeling), and child factors (e.g., children's enjoyment of an activity and their perceived self-efficacy for physical activity) determine a child's engagement in physical activity (Allison, 1996). Gender was also found to affect children's participation patterns (Law et al., 2006). When referring to typically developing children, previous studies showed that boys tend to participate in active types of rule-governed play in larger groups (Blatchford, 1998) and to engage more intensely in active physical activities, whereas girls tend to be more engaged in skill-based, self-improvement activities (Garton \& Pratt, 1991; King et al., 2006) and socializing (Posner \& Vandell, 1999). Girls have been observed to engage in more sedentary talking and to be in smaller groups (Blatchford, 1998). Law et al. (2006) and King et al. (2006), who evaluated participation patterns among children with complex physical disabilities (including CP), also reported that girls participated in more social activities.

Law (2002) developed a model of children's recreation and leisure participation, which is divided into formal and informal activities. Formal activities include structured activities that involve rules or goals and have a formally designated coach, leader, or instructor (e.g., music or art lessons, organized sports, youth groups). Informal activities have little or no planning and are often initiated by oneself (e.g., reading, socializing with friends, playing). Participation in occupations encompasses several dimensions: the person's preferences and interests; what he or she does, how often, where, and with whom; and how much enjoyment and satisfaction he or she experiences. Therefore, when measuring participation, all those dimensions should be considered. Such understanding may assist in planning interventions to enhance children's participation or to design effective policies and programs on a broader, systems level (King, Law, et al., 2003).

To measure participation, King et al. (2004) developed the Children's Assessment of Participation and Enjoyment
(CAPE), which is based on a child's self-report. Self-report assessments for children are important for both clinical and research use. They are based on the client-centered approach (Law \& Mills, 1998), giving children a greater voice in their therapy. Participation in occupation is best understood from the perspective of the child who engages in it (Primeau $\&$ Ferguson, 1999) because it is the child who experiences his or her activities. Thus, in the clinical practice, this input may contribute meaningfully to the assessment and determination of personal treatment goals related to out-of-school occupations.

The literature emphasizes that, by understanding the factors and processes influencing whether and how people with disabilities engage in activity, we can encourage their participation by removing barriers to active involvement in recreation and leisure activities (Law et al., 1999). Previous studies examined patterns of participation among children with physical disabilities (e.g., King et al., 2006; Law et al., 2006). However, information regarding participation patterns of people with CP, especially those of youths, is lacking (King, Law, et al., 2003). The purpose of this study was to investigate the participation in activity of children with $\mathrm{CP}$ compared with typically developing peers using the CAPE. The study's research questions were as follows: (1) Do differences in patterns of participation exist between children with CP and typical peers? (2) How does gender associate with participation patterns?

\section{Method}

\section{Participants}

Fifty-two children ages $12-16$ years were included in the study. The study group consisted of 22 Israeli children (10 boys and 12 girls, mean age $=14.0 \pm 1.4$ years) with $\mathrm{CP}$ (diplegia, quadriplegia, or athetosis) who were students at a special school for children with CP, as found in several places in Israel. The study group participants used mobility aids, such as a power wheelchair or a walker. Their IQs ranged from mild retardation to the lower end of the normal spectrum. Before completing the CAPE, the occupational therapist as well as the children themselves verified that they were capable of completing the CAPE independently. According to their occupational therapists, their communication skills were good enough to allow them to understand the assessment's instructions. Three of the participants could not respond to the assessment's questions verbally and thus used a communication board.

The group without disability consisted of 30 children (9 boys and 21 girls, mean age $=13.43 \pm 1.11$ ) who were students at a mainstream public school from the same geographic area 
as the CP children's school and from similar socioeconomic backgrounds. All participants attended school and did not have mental disorders or chronic diseases in addition to their primary diagnosis.

The parents of all children signed consent forms for the participation of their children in this study.

\section{Instruments}

All participants completed the CAPE (King et al., 2004). The CAPE is designed to document how children ages 6-21, with or without disabilities, participate in everyday activities. It consists of cards with drawings of children and youths participating in different activities during their time outside of formal school. Each card is presented to participants with a drawing of the activity and a phrase (in words) describing the activity. The CAPE gathers information about participation frequency, enjoyment, location, and with whom participation is carried out. The CAPE version used in this study contained 49 items of 14 formal activities that are structured activities; that involve rules or goals; and that have a formally designated coach, leader, or instructor, for example, taking art lessons, learning to dance, swimming, and getting extra help for schoolwork from a tutor. The other 35 items refer to informal activities that have little or no planning and often are initiated by oneself (e.g., reading, hanging out, going to a party); (Law et al., 2000).

The children were asked to indicate, using a 7-point scale, which activities they participated in and how often they had engaged in the activities in the past 4 months. Three types of scores are generated from the CAPE measure: (1) participation diversity (a count of the number of activities in which the child has participated over the past 4 months), (2) intensity (calculated by dividing the sum of item frequency by the number of activities), and (3) enjoyment (calculated by dividing the sum of enjoyment scores by the number of activities). Diversity, intensity, and enjoyment are calculated for the total number of activities, as well as separately for informal and formal activities. In addition, scores for five types of activities, derived through factor analysis of participation preference data, were calculated: recreational, active physical, social, skill-based, and selfimprovement/educational activities.

Further information was obtained on the activities in which the children participated - including (1) with whom they typically carried out the activity (e.g., parent, friend), (2) where they carried out the activity (e.g., home, friend's house), and (3) how much they enjoyed the activity—rated on a 5 -point scale.

To analyze data regarding with whom and where the child participated in activity, two scores were calculated for each scale: the number of activities performed by the child alone and the number of activities performed in the community. Because children do not perform the same number of activities in each scale, the scores were calculated relative to the number of activities on each scale that were performed by the child. These scores were expressed in percentages, with each representing the percentage of activities on each scale that were performed by the child either alone or in the community.

Test-retest reliability for the formal, informal, and total participation intensity scores of the CAPE ranged from .64 to .86 (based on random effects intraclass correlation coefficients) when assessed with 48 children and youths with disabilities.

\section{Procedure}

After this study was approved by the ethics committee of the Ministry of Education and the written informed consent was signed by the parents, data were gathered in one phase in the child's home or at school by an occupational therapist.

\section{Statistical Analysis}

The general linear model was used to test the significance of group $\times$ gender interactions. Two-way analyses of variance were performed on each of the CAPE scores, using a 2 (groups) $\times 2$ (genders) design. Post hoc Bonferroni procedure tested the significant differences between the means. In addition, effect size was calculated using the partial eta-square $\left(\eta_{p}^{2}\right)$ values based on the following formula: $\eta_{p}^{2}=S S_{b} /\left(S S_{b}+S S_{w}\right)$. These values were interpreted according to Cohen (1977) classification, where $\eta_{p}^{2}=.01$ is considered as a small, $\eta_{p}^{2}=$ .06 as a medium, and $\eta_{p}^{2}=.14$ as a large effect size. Effect size values were calculated using $\eta_{p}^{2}$ and not a more rigorous index, such as $\eta^{2}$, because the two indexes differ when total sample size is approximately 50 or more (Stevens, 2002).

\section{Results}

\section{Group Differences}

Significant difference was found between the groups in the diversity scores of all the CAPE scales, except for formal and skill-based activities. Significant differences between groups were also found in the intensity of the total, informal, social, and skill-based scales (see Figures 1 and 2). These results indicated that typically developing youths engaged in a broader range of activities (performed on the average 26.2 activities out of 49) and more frequently (approximately once a month) than the youths with CP (performed on the average 16.8 activities out of 49 , approximately twice in the last 4 months). Effect size values indicated medium to strong 


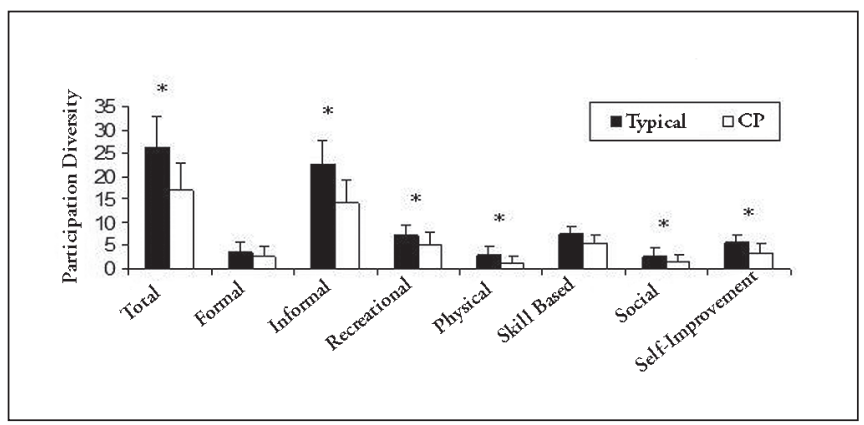

Figure 1. Participation diversity between groups.

Note. $C P=$ cerebral palsy

${ }^{*}$ Indicates significant differences between groups $(p<.05)$.

effect (Table 1, Figures 1 and 2). No significant differences were found between the groups in the enjoyment score of all scales, except for the self-improvement scale, in which the level of enjoyment of youths with $\mathrm{CP}(M=3.71, S D=0.96)$

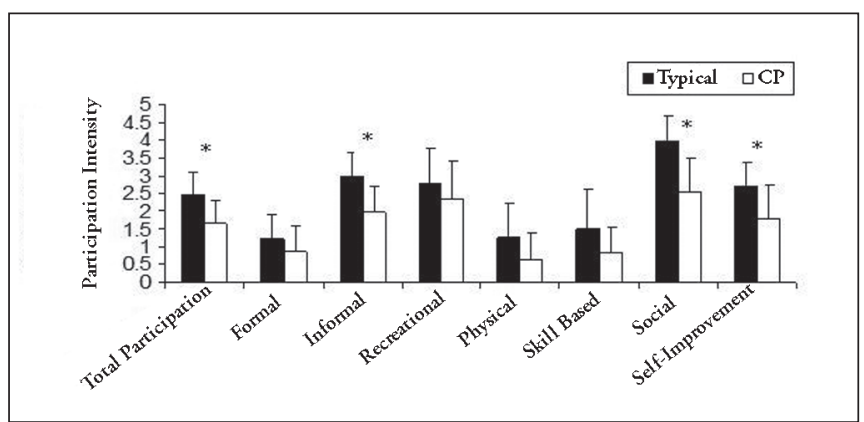

Figure 2. Participation intensity between the two groups.

Note. $C P=$ cerebral palsy.

${ }^{*}$ Indicates significant differences between groups $(p<.05)$.

was higher than typical youths $(M=3.11, S D=0.66)$. Group type could explain $11 \%$ of the variance of the enjoyment level in self-improvement activities.

Table 1. Analysis of Variance for Diagnosed Group and Gender in CAPE Variables

\begin{tabular}{|c|c|c|c|c|c|c|}
\hline \multirow[b]{2}{*}{ CAPE Variable } & \multicolumn{2}{|c|}{ Group } & \multicolumn{2}{|c|}{ Gender } & \multicolumn{2}{|c|}{ Group $\times$ Gender } \\
\hline & $F(d f)$ & $\eta_{p}^{2 *}$ & $F(d f)$ & $\eta_{p}^{2}$ & $F(d f)$ & $\eta_{p}^{2}$ \\
\hline \multicolumn{7}{|l|}{ Total activities } \\
\hline Diversity & $17.85(1,46)^{\star \star *}$ & .28 & $0.11(1,46)$ & .002 & $1.76(1,46)$ & .037 \\
\hline Intensity & $12.65(1,46)^{\star * *}$ & .21 & $0.18(1,46)$ & .004 & $0.88(1,46)$ & .019 \\
\hline Enjoyment & $0.81(1,46)$ & .02 & $11.23(1,46)^{\star \star *}$ & .190 & $3.39(1,46)$ & .069 \\
\hline \multicolumn{7}{|c|}{ Formal activities } \\
\hline Diversity & $0.19(1,42)$ & .005 & $0.25(1,42)$ & .006 & $2.18(1,42)$ & .049 \\
\hline Intensity & $0.59(1,42)$ & .014 & $0.37(1,42)$ & .009 & $2.16(1,42)$ & .049 \\
\hline Enjoyment & $0.45(1,42)$ & .011 & $1.36(1,42)$ & .032 & $2.48(1,42)$ & .056 \\
\hline \multicolumn{7}{|c|}{ Informal activities } \\
\hline Diversity & $26.37(1,46)^{\star \star *}$ & .364 & $0.90(1,46)$ & .019 & $0.36(1,46)$ & .018 \\
\hline Intensity & $16.26(1,46)^{\star \star *}$ & .261 & $1.08(1,46)$ & .030 & $0.66(1,46)$ & .004 \\
\hline Enjoyment & $0.56(1,46)$ & .012 & $12.78(1,46)^{\star \star *}$ & .217 & $0.15(1,46)$ & .043 \\
\hline \multicolumn{7}{|c|}{ Recreational activities } \\
\hline Diversity & $6.46(1,46)^{*}$ & .123 & $0.23(1,46)$ & .005 & $0.65(1,46)$ & .014 \\
\hline Intensity & $2.36(1,46)$ & .049 & $0.41(1,46)$ & .009 & $1.27(1,46)$ & .027 \\
\hline Enjoyment & $0.004(1,46)$ & .000 & $1.22(1,46)$ & .026 & $0.13(1,46)$ & .003 \\
\hline \multicolumn{7}{|c|}{ Active physical activities } \\
\hline Diversity & $5.73(1,45)^{*}$ & .141 & $3.98+(1,45)$ & .102 & $0.05(1,45)$ & .001 \\
\hline Intensity & $1.65(1,45)$ & .045 & $3.75(1,45)$ & .097 & $0.03(1,45)$ & .001 \\
\hline Enjoyment & $0.01(1,45)$ & .000 & $0.70(1,45)$ & .020 & $2.99(1,45)$ & .079 \\
\hline \multicolumn{7}{|l|}{ Social activities } \\
\hline Diversity & $16.01(1,46)^{\star \star \star}$ & .258 & $1.42(1,46)$ & .030 & $6.40(1,46)^{*}$ & .012 \\
\hline Intensity & $24.41(1,46)^{\star \star \star}$ & .348 & $2.42(1,46)$ & .050 & $4.33(1,46)^{*}$ & .080 \\
\hline Enjoyment & $2.04(1,46)$ & .043 & $17.62(1,46)^{\star \star *}$ & .270 & $4.52(1,46)^{*}$ & .090 \\
\hline \multicolumn{7}{|c|}{ Skill-based activities } \\
\hline Diversity & $0.96(1,37)$ & .025 & $1.45(1,37)$ & .038 & $0.76(1,37)$ & .020 \\
\hline Intensity & $1.59(1,37)$ & .041 & $1.08(1,37)$ & .028 & $2.14(1,37)$ & .055 \\
\hline Enjoyment & $0.73(1,37)$ & .019 & $0.46(1,37)$ & .012 & $0.43(1,37)$ & .012 \\
\hline \multicolumn{7}{|c|}{ Self-improvement activities } \\
\hline Diversity & $15.04(1,45)^{\star \star \star}$ & .251 & $2.84(1,45)$ & .059 & $0.50(1,45)$ & .011 \\
\hline Intensity & $9.28(1,45)^{\star \star \star}$ & .171 & $2.37(1,45)$ & .050 & $0.003(1,45)$ & .000 \\
\hline Enjoyment & $5.71(1,45)^{\star}$ & .113 & $2.02(1,45)$ & .043 & $5.68^{*}(1,45)$ & .112 \\
\hline
\end{tabular}

Note. CAPE $=$ Children's Assessment of Participation and Enjoyment (King et al., 2004).

${ }^{\star} p<.05 .{ }^{* \star} p<.01 .{ }^{* \star *} p<.001$. 


\section{Gender Differences}

A significant main effect for gender was found only in enjoyment scores for the total activity, informal activity, and social activity scales. Those results indicated that girls have a significantly higher lever of enjoyment than boys in the social, informal activities, and total participation scales of the CAPE. Effect size values indicated a relatively strong effect. No significant main effects of gender on intensity and diversity scores were found (see Table 1).

A significant interaction effect was found between group type and gender for diversity, intensity, and enjoyment on the social activities scale and for the enjoyment score of the self-improvement scale. The significant interaction indicates that the effect of the group type on participation diversity and intensity in the social activity scale was dependent on gender with medium effect size values. Post hoc tests indicate that the diversity and intensity of participation in social activity of typically developing girls was significantly higher when compared with girls with CP. In addition, significant differences in diversity and intensity of the social activity scale were found between genders among typically developing youths. Girls' level of diversity and intensity was significantly higher than boys in the typically developing group (see Figure 3 and Table 1).

A significant interaction effect was found between group type and gender with respect to the enjoyment score of selfimprovement activity scale. This interaction effect could explain $11.2 \%$ of the variance of the enjoyment score. Post hoc tests indicate that level of enjoyment of girls with $\mathrm{CP}$ (on the self-improvement skills scale) is higher than that of boys with $\mathrm{CP}$ and girls in the typically developed group (Figure 4).

When evaluating the proportion of activities done alone, youths with CP participated in proportionally more activities

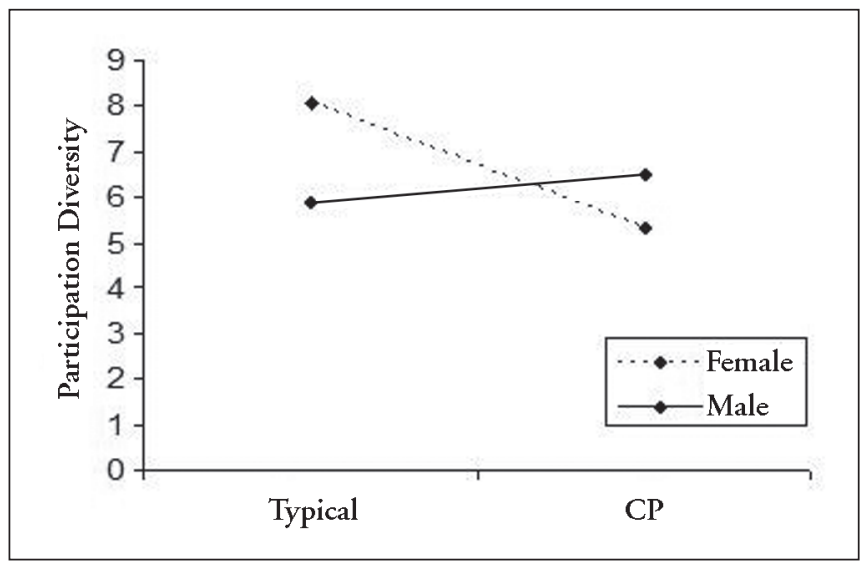

Figure 3. Interaction effect between group type and gender in participation diversity on the Social Activity scale.

Note. $\mathrm{CP}=$ cerebral palsy.

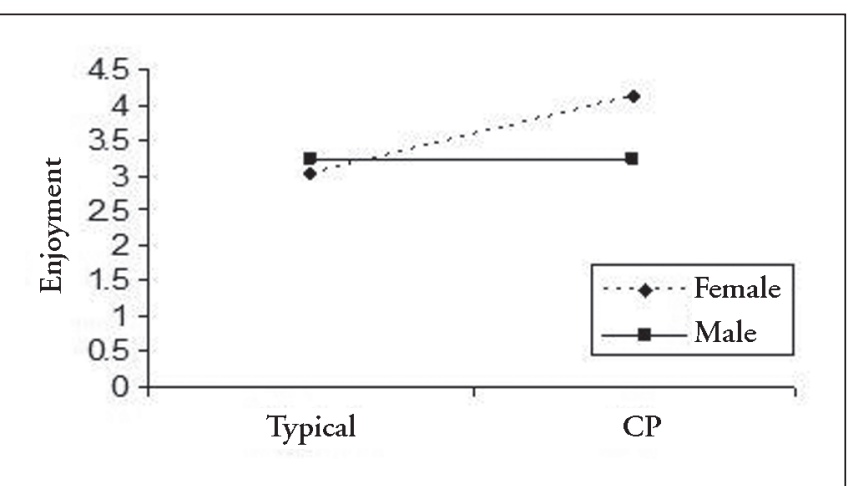

Figure 4. Interaction effect between group type and gender in participation enjoyment on the Self-Improvement Activity scale. Note. $C P=$ cerebral palsy.

alone than typically developed youth only in recreational activities $\left(F[1,46]=6.87, p=.012, \eta_{p}^{2}=.13\right)$. In addition, results of the main effect of gender revealed that boys participated in proportionally more social activities alone than girls, regardless of the group type (CP/typical; $F[1,46]=5.32$ , $\left.p=.026, \eta_{p}^{2}=.104\right)$. No significant interaction effect was found in the proportion of participation alone between gender and group type.

When evaluating the proportion of activities done at home the results showed that, youths with cerebral palsy participated proportionally more at home then did the typically developing youths in recreational activities, informal activities, and total participation scales (Table 2). Three significant interactions were found between gender and group type in self-improvement, informal, and total participation. Post hoc tests indicated that typically developing boys performed proportionally more activities at home than did boys with CP on the self-improvement scale. Girls with CP performed proportionally more activities at home than typically developing girls on the informal and total participation scales (Figure 5).

\section{Discussion}

The current study expands our knowledge of youths with $\mathrm{CP}$ by comparing their participation in activities with that of typical youths. Youth is a time of transition from childhood to adulthood and a time when youths leave the routine of school attendance. As in other transition stages, understanding this stage in life is crucial to ensure an optimal transition (Stevenson et al., 1997).

In most CAPE scales, typically developing youths are engaged in a larger number of activities than are youths with CP. This result supports other studies in which participation of people with physical disabilities was found to be lower than that of typical people (Magill-Evans \& Restall, 1991). 


\begin{tabular}{|c|c|c|c|c|c|c|}
\hline & \multicolumn{2}{|c|}{ Group } & \multicolumn{2}{|c|}{ Gender } & \multicolumn{2}{|c|}{ Group $\times$ Gender } \\
\hline & $F(d f)$ & $\eta_{p}^{2 *}$ & $F(d f)$ & $\eta_{p}^{2}$ & $F(d f)$ & $\eta_{p}^{2}$ \\
\hline$\overline{\text { Total }}$ & $14.34(1,46)^{\star \star \star}$ & .238 & $0.764(1,46)$ & .016 & $5.14(1,46)^{*}$ & .100 \\
\hline Formal & $1.450(1,42)$ & .033 & $0.190(1,42)$ & .004 & $0.04(1,42)$ & .001 \\
\hline Informal & $14.53(1,46)^{\star \star \star}$ & .240 & $0.023(1,46)$ & .006 & $5.06(1,46)^{*}$ & .099 \\
\hline Recreational & $17.88(1,46)^{* * *}$ & .280 & $0.073(1,46)$ & .002 & $0.38(1,46)$ & .001 \\
\hline Physical & $0.44(1,46)$ & .012 & $1.440(1,46)$ & .012 & $1.47(1,46)$ & .040 \\
\hline Social & $2.82(1,46)$ & .058 & $1.090(1,46)$ & .023 & $3.73(1,46)$ & .075 \\
\hline Skill based & $0.213(1,37)$ & .006 & $1.190(1,37)$ & .031 & $0.51(1,37)$ & .013 \\
\hline Self-improvement & $1.320(1,45)$ & .029 & $0.001(1,45)$ & .000 & $11.73(1,45)^{\star \star}$ & .207 \\
\hline
\end{tabular}

${ }^{\star} p<.05 .{ }^{* *} p<.01 .{ }^{* *} p<.001$.

No significant differences were found between the groups with respect to diversity and intensity of formal and skill-based activities. This finding may be related to the fact that most often schoolteachers or therapists focus on formal activities with goals and rules, as well as improving skillsbased activities. Such activities, like swimming, gymnastics, horseback riding, or playing a musical instrument, are an integral part of the study group's school curriculum. This may also explain the nonsignificant difference between the groups in the intensity of the recreational and active physical activities, which include puzzles, crafts, playing with pets, racing, and water sports. Those activities are also part of the school curriculum and therapy sessions. Yet, it is important to remember that, in the informal category, where children's participation is higher than the formal category, significant differences between the two groups were found. Similar to our results, Law et al. (2006), who examined patterns of participation among children with complex physical disabilities, found that for participation diversity, these children participated more in informal activities than in formal activities. These researchers claimed that access to formal activities is

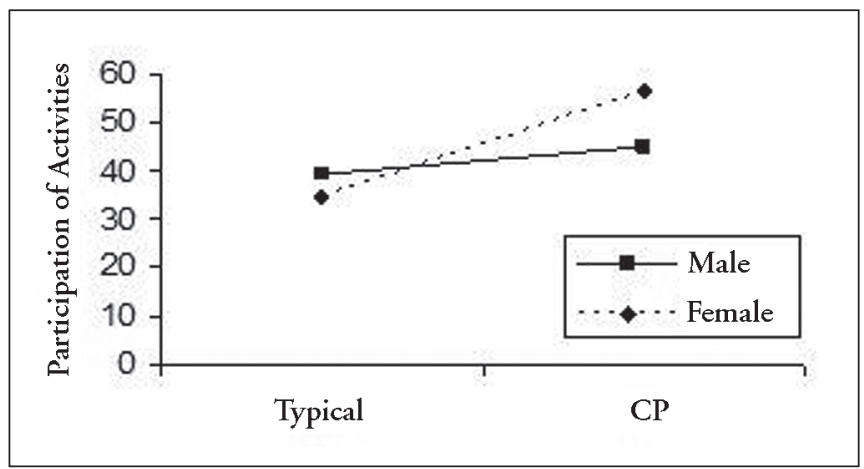

Figure 5. Interaction effect between group type and gender of the percentage of total activities performed at home.

Note. $\mathrm{CP}=$ cerebral palsy. different from access to informal activities, which are less affected by physical or institutional environmental barriers.

In the current study, no differences were found between groups in the level of enjoyment in most CAPE scales. Henry (1998) stated that, although the needs of people with disabilities differ in a variety of ways from their counterparts without disabilities, they are also, to a large extent, the same as those of typical children. These results may indicate that a higher diversity and intensity of participation level does not necessarily ensure better outcomes. Although youths with CP had a lower diversity and intensity of participation level, they did not indicate less enjoyment while participating.

Interestingly, girls with CP expressed a higher level of enjoyment than both the boys with $\mathrm{CP}$ and the typically developing girls on the self-improvement scale. King et al. (2006) reported that girls with physical disabilities participated more in self-improvement activities and showed a higher enjoyment level on this scale than did boys with physical disabilities. This scale includes activities such as writing letters and reading; both activities are more readily available for people with CP because of environmental modifications. Additional activities in this scale, such as going to a temple or to a public library, are not always accessible for people with CP. However, the higher enjoyment level from such activities suggests that participation in such activities is important for people with CP and may contribute to their feeling an integral part of their family and community. This finding supports the need for legislation that would require environmental adaptations to preexisting community facilities and construction of public buildings that are accessible to people with disabilities, as well as accessible transportation and accessible information about current and future programs (King, Cathers, Miller Polgar, MacKinnon, \& Havens, 2000; Law \& Dunn, 1993; Law et al., 1999; Schlaff, 1993).

The American Journal of Occupational Therapy 
When evaluating participation in social activities, typically developing girls showed a higher diversity and intensity of participation level than all other participants. This finding supports previous studies about typical children (Posner \& Vandel, 1999; Blatchford, 1998), as well as the studies of Law et al. (2006) and King et al. (2006) on children with complex physical disabilities. It appears that in the current study, the social participation of girls with $\mathrm{CP}$ was most affected.

In the current study, youths with CP participated alone proportionally more in recreational activities compared with the typically developing youths. Typical youths may perform these activities with friends, but the physical restrictions of youths with CP may limit them to performing these activities in special environments, at school, or at home, where the needed physical or human environmental adaptations are available. People with CP might participate more at home than typically developing youths because parents can help them, in contrast to the typical group that is more independent and can spend more time outside the home. Indeed, previous literature mentioned that the activities of children with $\mathrm{CP}$ are mostly performed at home and are dependent on adults. As children grow, more activities are shifted to the community and done independently. Participation changes as children with disabilities transition to adolescence, with fewer activities occurring outside the home (King, Cathers, et al., 2003; Pollock \& Stewart, 1990; Stevenson et al., 1997). This study exhibits this transition, indicating that youths with disabilities, such as $\mathrm{CP}$, might experience growing isolation as they mature.

The social isolation of children with physical disabilities, such as CP (Magill-Evans \& Restall, 1991; Stevenson et al., 1997), should receive further attention because feelings of social isolation and loneliness experienced by adolescents with disabilities may lead to a limited amount of activities and encourage a passive life style (King et al., 2000; Law et al., 1999; Tamm \& Prellwitz, 2001). Doubt and McColl (2003), who evaluated the social integration of teenagers with physical disabilities attending regular schools, found that these students identified several intrinsic and extrinsic factors that limited their integration into their school community. Intrinsic factors included the physical limitation and the perceptions of the students with disabilities about physical disability that made them feel that they would not be accepted by their typical peers. Extrinsic factors included the attitudes and behavior of peers without disabilities (participants experienced being treated by some of their peers without disabilities as though they were younger or less competent or less intelligent) and inaccessible extracurricular activities, particularly athletics.

These outcomes may have important implications on intervention programs that should focus on the people fac- tors as well as on environmental factors that may enhance the social isolation especially during youth, when social activities are of great importance (Stevenson et al., 1997).

People with disabilities often cite "being believed in by others" as a crucial factor determining their success in life (King et al., 2000; King, Cathers, et al., 2003). Moving toward community reintegration of persons with disabilities, developing their ability to participate in leisure time independently, and mainstreaming these people into community living facilities maybe achieved by encouraging typical youth volunteers to contact their peers with disabilities and assist them in becoming more involved in community activities (Fink, 2005; Hanlon, Rosenberg, \& Clasby, 2007; Margalit, 1981).

Such attitudes may also contribute to the development of social experiences of adolescents with CP and the reduction of negative stereotypes (Law et al., 1999). Law et al. (2004) also highlighted the need to move beyond diagnosis and to focus on other personal and environmental factors as major predictors of participation in activity. Future studies are required to investigate which factors can enhance the participation of these people. This information will allow service providers, parents, managers, and policymakers to know which intrapersonal, interpersonal, and environmental factors are the most important determinants of participation of children with disabilities; how these factors limit or enhance participation; and whether these factors change as children age. Ultimately, this information may contribute to planning appropriate interventions as well as to designing effective policies and programs on a broader, systems level.

Finally, data collection tends to focus on parent- or teacher-identified issues (Missiuna \& Pollock, 2000); however, the ability to collect information directly from the client may be relevant to client-centered and evidence-based practice. As King et al. (2006) mentioned, service providers could discuss the match between activities and the children's skill level with children and families to ensure that selected activities provide opportunities for children's skill development.

\section{Limitations}

The current study is based on a small sample from a specific geographic area and refers to specific ages. In addition, no matching exists between genders of both groups. These limitations were a result of the effort to find participants who answer the inclusion criteria of this study and should be considered in the interpretations of the study's results. Because the current study is an exploratory study, it is recommended that it be repeated with larger, matched samples to fully understand the effects of physical abilities and gender on participation of people with CP. Elaborating the knowledge on these effects 
may allow policy makers, health professionals, and community agencies to design the most effective and accessible programs for the promotion of the participation of people with special needs. Although the use of a less rigorous index to estimate effect size is justified by the sample size (Stevens, 2002), this study stands in the low end of the required sample size. Future studies might consider a larger sample size to verify that effect size values are measured accurately.

\section{Acknowledgments}

We thank Nava Gafni, Galia Burg, and Sharon Werech for their contribution to the study and all the children for their participation.

\section{References}

Allison, K. R. (1996). Predictors of inactivity: An analysis of the Ontario Health Survey. Canadian Journal of Public Health, $87,354-358$

Blatchford, P. (1998). Social life in school. London: Falmer.

Brown, M., \& Gordon, W. A. (1987). Impact of impairment on activity patterns of children. Archives of Physical Medicine and Rehabilitation, 68, 828-832.

Cohen, J. (1977). Statistical power analysis for the behavioral sciences (rev. ed.). New York: Academic Press.

Doubt, L., \& McColl, M. A. (2003). A secondary guy: Physically disabled teenagers in secondary schools. Canadian Journal of Occupational Therapy, 70, 139-151.

Fink, D. B. (2005). Toward ethical approaches to the inclusion of peers with disabilities. New Directions for Youth Development, 108, 77-87.

Garton, A. F., \& Pratt, C. (1991). Leisure activities of adolescent school students: Predictors of participation and interest. Journal of Adolescence, 14, 305-321.

Hanlon, N., Rosenberg, M., \& Clasby, R. (2007). Offloading social care responsibilities: Recent experiences of local voluntary organizations in a remote urban centre in British Columbia, Canada. Health and Social Care in the Community, 15, 343-351.

Henry, A. D. (1998). Development of a measure of adolescent leisure interests. American Journal of Occupational Therapy, 52, 531-539.

King, G., Cathers, T., Brown, E., Specht, J. A., Willoughby, C., Miller Polgar, J., et al. (2003). Turning points and protective processes in the lives of people with chronic disabilities. Qualitative Health Research, 13, 184-206.

King, G. A., Cathers, T., Miller Polgar, J., MacKinnon, E., \& Havens, L. (2000). Success in life for older adolescents with cerebral palsy. Qualitative Health Research, 10, 734-749.

King, G., Law, M., King, S., Hurley, P., Hanna, S., \& Kertoy et al. (2006). Measuring children's participation in recreation and leisure activities: Construct validation of the CAPE and PAC. Child: Care, Health and Development, 33, 28-39.

King, G., Law, M., King, S., Hurley, H., Rosenbaum, P., Hanna, S., et al. (2004). CAPE/PAC manual: Children's Assessment of Participation and Enjoyment and Preferences for Activities of Children. San Antonio, TX: Psychological Corporation.
King, G., Law, M., King, S., Rosenbaum, P., Kertoy, M., \& Young, N. (2003). A conceptual model of the factors affecting the recreation and leisure participation of children with disabilities. Physical and Occupational Therapy in Pediatrics, 23, 63-90

Law, M. (2002). Participation in the occupations of everyday life. American Journal of Occupational Therapy, 56, 640-649.

Law, M., \& Dunn, W. (1993). Perspectives on understanding and changing the environments of children with disabilities. Physical and Occupational Therapy in Pediatrics, 13, 1-17.

Law, M., Finkelman, S., Hurley, P., Rosenbaum, P., King, S., King, G., et al. (2004). Participation of children with physical disabilities: Relationships with diagnosis, physical function, and demographic variables. Scandinavian Journal of Occupational Therapy, 11, 156-162.

Law, M., Haight, M., Milroy, B., Willms, D., Stewart, D., \& Rosenbaum, P. (1999). Environmental factors affecting the occupations of children with physical disabilities. Journal of Occupational Science, 6, 102-110.

Law, M., King, G., King, S., Keroy, M., Hurley, P., Rosenbaum, P., et al. (2006). Patterns of participation in recreational and leisure activities among children with complex physical disabilities. Developmental Medicine and Child Neurology, 48, 337-342.

Law, M., King, G., Rosenbaum, P., Kertoy, M., King, S., Young, N., et al. (2000). The participation of children with physical disabilities. Bethesda, MD: National Institutes of Health.

Law, M., \& Mills, J. (1998). Client-centered occupational therapy. In M. Law (Ed.), Client-centered occupational therapy (pp. 1-18). Thorofare, NJ: Slack.

Magill-Evans, J. E., \& Restall, G. (1991). Self-esteem of persons with cerebral palsy: From adolescence to adulthood. American Journal of Occupational Therapy, 45, 819-825.

Margalit, M. (1981). Leisure activities of cerebral palsied children. Israel Journal of Psychiatry and Related Sciences, 18, 209-214.

Meijer, S. A., Sinnema, G., Bijstra, J. O., Mellenbergh, G. J., \& Wolters, W. H. (2000). Social functioning in children with a chronic illness. Journal of Child Psychology and Psychiatry, and Allied Disciplines, 41, 309-317.

Missiuna, C., \& Pollock, N. (2000). Perceived efficacy and goal setting in young children. Canadian Journal of Occupational Therapy, 67, 101-109.

Moe, P. G., \& Seay, A. A. (1993). Neurologic and muscular disorders. In W. E. Hathaway, W. W. Hay, J. R. Groothuis, \& J. W. Paisley (Eds.), Current paediatric diagnosis and treatment (11th ed., pp. 675-732). Lebanon: Appleton \& Lange.

Pollock, N., \& Stewart, D. (1990). A survey of activity patterns and vocational readiness of young adults with physical disabilities. Canadian Journal of Rehabilitation, 4, 17-26.

Posner, J. K., \& Vandell, D. L. (1999). After-school activities and the development of low-income urban children: A longitudinal study. Developmental Psychology, 35, 868-879.

Primeau, L. A., \& Ferguson, J. M. (1999). Occupational frame of reference. In P. Kramer \& J. Hinojosa (Eds.), Frames of reference for pediatric occupational therapy (pp. 469-516). Philadelphia: Williams \& Wilkins.

Schlaff, C. (1993). From dependency to self-advocacy: Redefining disability. American Journal of Occupational Therapy, 47, 943-948. 
Stevens, J. (2002). Applied multivariate statistics for the social sciences (4th ed.). Mahwah, NJ: Erlbaum.

Stevenson, C. J., Pharoah, P. O., \& Stevenson, R. (1997). Cerebral palsy-The transition from youth to adulthood. Developmental Medicine and Child Neurology, 39, 336-342.

Strauss, D., Shavelle, R., Reynolds, R., Rosenbloom, L., \& Day, S. (2007). Survival in cerebral palsy in the last 20 years: Signs of improvement? Developmental Medicine and Child Neurology, 49, 86-92.
Tamm, M., \& Prellwitz, M. (2001). "If I had a friend in a wheelchair": Children's thoughts on disabilities. Child: Care, Health, and Development, 27, 223-240.

World Health Organization. (2001). The international classification of functioning, disability, and health. Retrieved July 17, 2007, from www.who.int/classifications/icf/en/
The New

IDEA:

An Occupational Therapy Toolkit,

2nd Edition

Leslie L. Jackson, MEd, OT, Editor

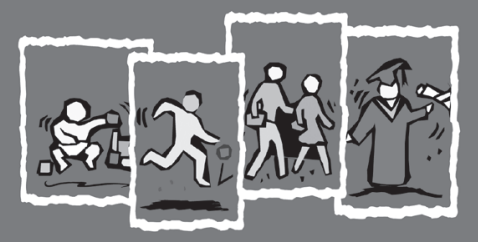

The New IDEA: An Occupational Therapy Toolkit, 2nd Edition

The most comprehensive resource on the role of occupational therapy and IDEA on the market today!

An interactive CD-ROM developed for occupational therapy practitioners, educators, researchers, and scientists. It contains key resources about the Individuals with Disabilities Education Act (IDEA) and other related federal legislation, and is designed as a research and training tool for occupational therapists and occupational therapy assistants to help improve early intervention and educational results for children and youth with disabilities.

This new Toolkit is great for occupational therapy practitioners who work with children with disabilities or in school settings.

Contents Include:

- Statutory and Regulatory Information and Resources in IDEA

- Statutory and Regulatory Information and Resources on No Child Left Behind

- Statutory and Regulatory Information and Resources on Early Childhood

- Additional Information/Resources for Occupational Therapy Practitioners, Educators, Researchers/Scientists Order \#4810A

\$49 for Members, \$69 for Nonmembers

AOTA PRESS

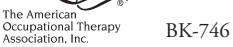

\section{Shop AOTA today! Call 877-404-AOTA or Shop online store.aota.org}

